\title{
O tempo e o espaço da escola: produção de conhecimento escolar e de saber profissional
}

\author{
Marli Dallagnol Frison* \\ José Cláudio Del Pino ${ }^{* *}$ \\ Jaqueline Paim Ceretta ${ }^{* *}$
}

\begin{abstract}
Resumo: Este artigo traz reflexões acerca de um processo de trabalho vivenciado no contexto de uma escola pública durante o desenvolvimento de uma proposta de ensino que trata de resíduos sólidos produzidos pela atividade humana. Reflete sobre o ensino de Química, considerando a sala de aula como espaço de interlocução e de produção de conhecimento escolar e de saber profissional. Propõe um ensino mais integrado e contextualizado e mostra a importância das relaçôes estabelecidas entre professores em formação inicial e professores em exercício para a constituição destes profissionais.
\end{abstract}

Palavras-chave: Conhecimento escolar, Formação profissional, Saberes docentes.

Doutoranda no Programa de Pós-Graduação Educação em Ciências: Química da Vida e Saúde - UFRGS. Professora do Departamento de Biologia e Química da Unijuí. Membro do Grupo Interdepartamental de Pesquisa em Educação nas Ciências (Gipec-Unijuí, RS). E-mail: marlif@unijui.edu.br

** Pós-doutor pela Universidade de Aveiro - Portugal. Doutor em Engenharia de Biomassa - UFRGS. Professor do PPG Educação em Ciências: Química da Vida e Saúde e de Química da UFRGS. E-mail: aeq@iq.ufrgs.br

*** Licencianda do Curso de Graduação em Química - Unijuí. Bolsista PIBIC - Unijuí. E-mail: jake.ceretta@gmail.com 


\begin{abstract}
This article brings reflections about a process of work carried out in the context of a public school during the development of a proposal of teaching which deals with the treatment of solid waste produced by the human activity. It reflects about the teaching of Chemistry, considering the classroom as a space of interlocution and production of school knowledge and professional learning. It proposes a more integrated and contextualized teaching and points out to the importance of the relationships established between teachers in initial education and teachers who already work in schools for the constitution of these professionals.
\end{abstract}

Keywords: School knowledge, Professional education, Teacher's knowledge.

\title{
Introdução
}

A avaliação do desempenho escolar de estudantes do Ensino Médio no Exame Nacional do Ensino Médio (Enem) e no Sistema Nacional de Avaliação da Educação Básica (Saeb) mostra que a escola não está dando conta de sua função que é a de favorecer a construção/reconstrução do conhecimento, por meio de situações problematizadoras e desafiantes, que conduzam à busca de informações e ao desenvolvimento em seu meio (BOFF; FRISON; ARAÚJO, 2005).

Pesquisas revelam que os estudantes e professores são vítimas de um ensino linear e fragmentado, que pouco contribui para a formação dos alunos e não está favorecendo a construção de um pensamento científico sobre o mundo. Entende-se que é função da escola oferecer oportunidades para a construção/ reconstrução do conhecimento por meio de situaçóes problematizadoras e desafiantes que conduzam à busca de informaçóes e ao desenvolvimento da sociedade e das pessoas. Nesta perspectiva, Maldaner e Araújo (1992, p. 20) salientam que o papel central da escola "[...] é o de investigar, problematizar e discutir os fatos, 
situações e coisas presentes no dia-a-dia dos educandos, de modo a thes viabilizar novas formas de compreensão das realidades vividas, à luz e através do acesso ao saber estruturado, a ciência”.

A escola de Ensino Médio, no entanto, está organizada de tal forma que pouco contribui para a aquisição de conhecimentos socialmente significativos e para a melhoria de vida dos estudantes. Na educação, a fragmentação do saber é originária da concepção empirista de ensinar e de entender o aprender, a qual argumenta que o saber vem de fora para dentro, ou seja, é externo ao sujeito e, por isso mesmo, não necessita estar conectado com a vivência dos estudantes.

Por outro lado Freire (1980) adverte que os estudantes são transformados em seres passivos que recebem os conteúdos, os conhecimentos, de forma autoritária, não lhes sendo permitido questionar ou sequer compreender seu papel como sujeitos socioculturais. Essas questôes colocam os educadores diante de uma realidade complexa, pois eles também se constituíram dentro de uma estrutura de conhecimentos isolados, ampliando-se, portanto, as dificuldades para propor e produzir mudanças em suas práticas concretizadas no espaço escolar. $\mathrm{O}$ que se percebe é que na maioria das vezes os professores seguem um currículo escolar com base em relações de conteúdos prontos, listados em livros didáticos, sem espaço para questionamento sobre o quê e para quê ensinar. Esse tipo de ensino produz altos índices de reprovações, especialmente na $\mathrm{l}^{\mathrm{a}}$ série do Ensino Médio, em que a Área de Ciências da Natureza, Matemática e suas Tecnologias tem uma participação significativa (FRISON, 2000).

Ao pensarmos os problemas do ensino, portanto, necessitamos avaliar "[...] os efeitos cada vez mais graves da compartimentação dos saberes e da incapacidade de articulá-los uns com os outros". Por outro lado, é preciso considerar que a "[...] aptidão para contextualizar e integrar é uma qualidade fundamental da mente humana, que precisa ser desenvolvida e não atrofiada" (MORIN, 2001, p. 16). 
Com base no exposto, defendemos uma concepção de ensino que leve em conta e valorize os seres humanos como sujeitos que tenham suas necessidades vitais, sociais, históricas, plenamente satisfeitas (SILVA, 2006). Assim, o currículo é compreendido como um sistema aberto e em permanente auto-organização (DOLL, 1997). Essa concepção reflete numa nova organização curricular que supera as ênfases disciplinares na busca de uma integração entre as áreas do conhecimento. Nessa perspectiva, a estruturação das organizações curriculares é imprescindível, à medida que se procura superar os limites impostos pelo sistema, criando outras possibilidades de proposições de currículo. Uma delas refere-se à elaboração coletiva e ao desenvolvimento de propostas de inovação curricular denominadas Situações de Estudo (SEs), que é

[...] conceitualmente rica, identificada nos contextos de vivência cotidiana dos estudantes fora e dentro da escola, sobre a qual eles têm o que dizer e, no contexto da qual, eles sejam capazes de produzir novos saberes expressando significados para tais saberes e defendendo seus pontos de vista (MALDANER; ZANON, 2001, p. 53).

Ao desenvolver os conteúdos escolares na forma de SE, entende-se que é possível fazer uma abordagem dos conceitos de Biologia, Física e Química de forma inter-relacionada, interdisciplinar e que proporcione reflexões sobre as questões sociais, culturais e as interações entre as Ciências da Natureza, suas Tecnologias e a Sociedade.

É com este propósito que apresentamos neste texto os resultados de uma pesquisa que se originou a partir das observações de algumas aulas ministradas numa escola pública estadual de Ensino Médio (EM), de Ijuí, RS, das quais participaram professores em formação inicial e em exercício, da escola e da universidade, além de estudantes da $\mathrm{l}^{\mathrm{a}}$ série deste nível de ensino durante o desenvolvimento da Situação de Estudo: Ambiente e vida: o ser humano neste contexto. As Situações de Estudo são entendidas como situações práticas que consideram a vivência 
dos estudantes, que superam a lógica puramente disciplinar, sem esquecer o sistema conceitual das disciplinas (AUTH et al., 2004).

Nos recortes trazidos, procuramos ressaltar a importância do conhecimento escolar para a compreensão de um problema de relevância social. Os diálogos produzidos durante as aulas foram gravados e transcritos, constituindo-se em fonte de pesquisa e em subsídios para a proposição de um currículo escolar com base na Situação de Estudo (SE). Para preservar a identidade de cada sujeito e, ao mesmo tempo, identificar as falas que aparecem no presente artigo, atribuímos nomes fictícios com letras iniciais $\mathrm{E}$ para caracterizar os estudantes de nível médio, C para professora da escola e I para professores em formação inicial.

\section{Aspectos metodológicos da pesquisa}

Esta pesquisa insere-se numa abordagem qualitativa, de investigação-ação, utilizando-se, como fontes de produção de dados as seguintes técnicas: filmagem de aulas desenvolvidas por duas professoras de Química, uma em formação inicial e outra em exercício; gravação dos encontros de estudo que ocorreram entre as professoras e entrevista semiestruturada com professora de Química da escola.

Optamos pela investigação-ação como estratégia metodológica por acreditarmos na afirmação de Carr e Kemmis (1988, p.106) de que "[...] a prática se modifica mudando a maneira de compreendê-la”, tornando-se necessário, para tanto, empreender uma pesquisa que alcance as pessoas implicadas na situação, fazendo com que os sujeitos envolvidos no processo tenham algo a dizer e a fazer, que lhes ofereça possibilidade de saber mais e de melhor atuar sobre a realidade educativa. Esta modalidade de investigação também encontra apoio em Elliott (1998) para quem a colaboração e a negociação entre professores formadores e professores da escola básica a teoria e a prática passam a se 
desenvolver de forma interativa dentro da escola e o contexto de aprendizagem se configura como problema para ambos.

A pesquisa envolveu uma estagiária do curso de Licenciatura em Química da Unijuí, uma professora formadora, uma professora de Química que atua no nível médio e uma turma de estudantes deste nível de ensino. Os recortes trazidos foram centrados nas falas dos estudantes, da estagiária e da professora de Química da escola que explicitam situações encontradas em práticas escolares vivenciadas por eles.

\section{O conhecimento escolar na compreensão de problemas ambientais}

Um dos grandes desafios da escola é oportunizar aos estudantes o acesso ao conhecimento para que cada indivíduo atinja um desenvolvimento pessoal, profissional e social (MORAES; GOMES, 2004). Para que aprendizagens significativas se efetivem, contudo, não podemos pensar um currículo linear e fragmentado, mas é necessário constituir práticas que oportunizem aos alunos exercer sua capacidade de pensar, pesquisar, construir e reconstruir, pois segundo Grundy (1987, apud SACRISTÁN, 1998, p. 14), “[...] o currículo não é um conceito, mas uma construção cultural. Isto é, não se trata de um conceito abstrato que tenha algum tipo de existência fora e previamente à existência humana. E, antes, um modo de organizar uma série de práticas educativas".

Assim, no objetivo de apresentar uma proposta de ensino mais integrado desenvolveu-se a SE "Ambiente e vida: o ser humano neste contexto", na qual a professora de Química buscou reconhecer os saberes já constituídos, pelos estudantes, no meio social e familiar e os seus entendimentos sobre questões ambientais de seu cotidiano. Para tanto, foram solicitados a se manifestar sobre seu entendimento em relação aos resíduos sólidos domésticos, buscando refletir a respeito de questões rela- 
cionadas à quantidade de lixo produzido por dia em sua casa; o destino dado para esse lixo; os problemas acarretados pelo mau gerenciamento; a constituição do lixo doméstico; a responsabilidade individual e coletiva quanto à produção e gerenciamento do lixo; o tipo de lixo que é mais prejudicial à saúde pública a curto e médio prazo; as alterações provocadas pelo ser humano ao meio ambiente e suas consequências.

A partir das interlocuções, estabeleceu-se uma reflexão sobre as possíveis orientações para estudar o lixo que os próprios estudantes produzem em suas residências, a começar pela questão da coleta. As professoras mostram séria preocupação com a conscientização dos estudantes em relação à separação do lixo, dando atenção especial aos reais hábitos dos alunos para que a conscientização possa se realizar a partir de uma situação vivida por eles.

Por meio das discussões estabelecidas em sala de aula e pelas manifestações dos estudantes, constatamos que os problemas relacionados à produção de resíduos sólidos e suas formas de tratamento não causavam preocupações aos estudantes. Assim, para que eles pudessem tomar consciência dos problemas que poderiam ser ocasionados pela produção de lixo e principalmente pelas formas inadequadas de seu destino, a professora de Química propôs aos alunos que trouxessem para a escola o lixo produzido em suas casas durante o período de dois dias.

Feito isso, foi-lhes solicitado que separassem os resíduos sólidos trazidos, utilizando como critério "lixo seco" e "lixo úmido”. Após a separação foi feita a pesagem dos diferentes tipos de resíduos, e, posteriormente, determinada a Composição Gravimétrica. Os valores obtidos foram registrados em um gráfico, o qual, após analisado, permitiu estabelecer a porcentagem em massa, $\mathrm{o}$ que possibilitou calcular a média de lixo produzido/dia/pessoa.

Nessa ocasião, observamos a dificuldade apresentada pelos alunos em calcular a porcentagem dos diferentes tipos de lixo. Conceitos básicos de Matemática, como transformação de unidades e regra de três ainda não haviam sido compreendidos 
pelos estudantes, mesmo já frequentando a $\mathrm{l}^{\mathrm{a}}$ série do Ensino Médio, conforme expressa o episódio a seguir, o qual se refere a um dos grupos constituídos em sala de aula durante a pesagem do lixo trazido por eles.

Lixo úmido: $3 \mathrm{~kg}$

Papel: $500 \mathrm{~g}$

Vidro: $600 \mathrm{~g}$

Plástico: $400 \mathrm{~g}$

Metal: $10 \mathrm{~g}$

Ao discutir os dados obtidos por um dos grupos, ocorreu a seguinte manifestação:

Eder: Professora, por que o plástico pesa menos se a quantidade que temos é maior? Penso que não pesamos corretamente.

Edson: Como pesa menos? Você não vê que o lixo úmido pesa 3 e o plástico pesa 400 ?

Esse diálogo mostra que Edson não se dá conta que as massas estão expressas em diferentes unidades: kg e grama, e que em cada $1 \mathrm{~kg}$ estão contidos 1000 gramas.

Mesmo com as dificuldades apresentadas pelos estudantes em compreender as quantidades reais de lixo produzido as professoras continuaram interagindo com eles na tentativa de fazê-los entender as unidades que expressam as quantidades de resíduos sólidos trazidos para a sala de aula. Além disso, outros mecanismos/técnicas foram empregados na tentativa de responder às limitações dos estudantes em relação ao conhecimento das unidades que expressam quantidades. A partir de diferentes tipos de embalagens que as indústrias utilizam para armazenar produtos, foram investigadas as quantidades de substâncias expressas em rótulos e, posteriormente, o destino que lhes é dado. Tais questões, que se referem diretamente ao consumo, raramente são abordadas em sala de aula, sugerindo uma educação tradicional. Tradicional não apenas o que diz respeito aos conteúdos e métodos de ensino dentro de cada disciplina, mas também em relação à inserção de novas áreas e conhecimentos que foram desenvolvidos numa sociedade de consumo como a nossa. 
Na medida em que as discussões iam acontecendo, novos questionamentos surgiam, havendo necessidade de novas atividades que permitissem ampliar o entendimento científico sobre a composição dos materiais encontrados. A professora Carla tenta fazer Éder e Edson entenderem a quantidade de lixo e se expressa dizendo:

Carla: Tente segurar em uma de suas mãos o lixo úmido e na outra o plástico.

Éder: O lixo úmido tem uma massa maior.

Edson: Mas ele ocupa um espaço menor.

Éder: Mas no gráfico ele ocupa a maior porcentagem, a maior parte.

As respostas de Éder e Edson deixam claro que eles não têm noção da constituição dos diferentes materiais presentes nos resíduos sólidos analisados, nem as características físicas e químicas de cada um deles. Conhecimentos sobre unidades de medida, porcentagem, regra de três, relação entre massa e volume, noções básicas de quantidades, especialmente as relacionadas à massa, parecem estar distantes do nível de abstração dos estudantes. Por outro lado, percebe-se que os diálogos estabelecidos em sala de aula propiciam aos estudantes e, também às professoras, uma reflexão mais profunda sobre os problemas que podem ser ocasionados quando esses resíduos não são tratados adequadamente, conforme manifestação de Iara:

Quando os resíduos são depositados no ambiente, com a ação do tempo e de fatores como temperatura, chuvas, entre outros, passam a se formar novas substâncias que acabam contaminando o solo e os lençóis de água, além da liberação de gases que contribuem para o efeito estufa e o aquecimento global. Conheço muitas pessoas que trabalham nesses depósitos de resíduos, onde trabalham como catadores, tirando dali o seu sustento, mas se expondo a muitos riscos como o de doenças como a dengue, a leptospirose, já que o lixão é um local apropriado para a proliferação de roedores e mosquitos que ficam depositados em latas e potes que contenham água parada, além de doenças como a hepatite 
e a cólera, que são adquiridas através da ingestão de água e alimentos contaminados. Essas doenças podem ser ocasionadas principalmente se as pessoas que trabalham nesses locais se alimentam de alimentos que são encontrados no lixo ali depositado.

A exposição de Iara mostra que, ao propor o desenvolvimento dos conteúdos escolares na forma de SE, ampliam-se as discussões para além dos conteúdos meramente disciplinares, exigindo do professor um conhecimento articulado que leve à compreensão de uma situação real, portanto da vivência dos estudantes. Assim, entendemos estar, também, contemplando as orientações propostas pelos Parâmetros Curriculares Nacionais (PCNs), uma vez que os conceitos são abordados de forma interdisciplinar, envolvendo outras áreas do conhecimento, e proporcionam a reflexão sobre questões sociais e culturais, mostrando-se relevante o desenvolvimento de posturas e valores pertinentes às relações entre os seres humanos, o conhecimento e $\mathrm{o}$ ambiente. $\mathrm{O}$ desenvolvimento desses valores envolve aspectos da vida social, como a cultura, as relações entre o homem e a natureza, o que contribui para a compreensão das diversas situações cotidianas que são apresentadas aos estudantes, conforme apontam os PCNs:

O ensino de Ciências Naturais também é espaço privilegiado em que as diferentes explicações sobre o mundo, os fenômenos da natureza e as transformações produzidas pelo homem podem ser expostos e comparados. É espaço de expressão das explicações espontâneas dos alunos e daquelas oriundas de vários sistemas explicativos. Contrapor e avaliar diferentes explicações favorece o desenvolvimento de postura crítica, questionadora e investigativa, de não aceitação a priori de idéias e informaçốes. Possibilita a percepção dos limites de cada modelo explicativo, inclusive dos modelos científicos, colaborando para a construção da autonomia de pensamento e ação (BRASIL, 1997, p. 22).

Do exposto, depreende-se que o confronto das concepções iniciais dos estudantes com aquelas expressas pelas professoras no espaço de sala de aula torna-se fundamental para a apropriação de significados diferenciados que, dialogicamente, constituirão sentidos a serem negociados. Assim, acredita-se que para chegar 
a uma aprendizagem significativa o aprendiz precisa ter acesso a um conhecimento escolar contextualizado, que deve ser alcançado a partir de uma inter-relação entre o conhecimento cotidiano e científico para que o aluno possa compreender os fenômenos que ocorrem a sua volta e propor soluções para situações novas que se apresentam, conforme salienta Lopes

O conhecimento escolar deve ser a didatização do conhecimento científico, mas não deve constituir-se como obstáculo ao desenvolvimento do conhecimento científico. A produção de conhecimento na escola não pode ter a ilusão de construir uma nova ciência [...]. Ao contrário, deve contribuir para o questionamento do senso comum, no sentido de não só modificá-lo em parte, como limitá-lo ao seu campo de atuação (LOPES, 1997, p. 43).

Nesse contexto, produzir um currículo escolar que considera os conhecimentos já produzidos pelos estudantes, por intermédio do seu meio social e cultural, possibilita, a eles, a aquisição de saberes com significado e sentido para os conceitos que se deseja sejam aprendidos. Considera-se importante destacar que os significados são produzidos na interação com o outro, e quem tem o papel de mediar esses significados é o professor. Nesse sentido, Machado afirma que

[...] o processo de elaboração de conhecimento é concebido como produção simbólica e material e constitui-se na dinâmica interativa das relações sociais envolvendo a linguagem e o funcionamento interpessoal. Isso significa dizer que a perspectiva histórico-cultural assume que é na interação com o outro que o sujeito se constitui e que se dá a elaboração conceitual (MACHADO, 1999, p. 50).

Neste viés, a escola se apresenta como uma modalidade específica de relação entre sujeito e objeto de conhecimento, resultante de um determinado processo histórico de construção dessa instituição, que pode ser compartilhada com seus alunos e suas famílias. A falta de conexão entre o que é desejado pela escola e o que é pretendido pelos alunos é, também, uma questão que deve ser considerada quando se fala em currículo escolar. 
Davidov, com base nos pressupostos de Vigotsky, corrobora com essa ideia e afirma que

[...] a escola deve ser capaz de desenvolver nos alunos capacidades intelectuais que lhes permitam assimilar plenamente os conhecimentos acumulados. Isso quer dizer que ela não deve se restringir à transmissão de conteúdos, mas principalmente ensinar o aluno a pensar, ensinar formas de acesso e apropriação do conhecimento elaborado, de modo que ele possa praticá-las autonomamente ao longo de sua vida, além de sua permanência na escola (DAVIDOV, 1998, p. 3).

Para Oliveira (1997), no entanto, a escola é uma instituição social na qual o desenvolvimento cognitivo dos sujeitos é parte da atividade principal da própria instituição. A escola promove, desenvolve, avalia e julga o desempenho escolar dos estudantes. Emergem daí, claramente, diferenças entre indivíduos e entre grupos, além daquelas individuais, presentes em qualquer situação social, além daquelas culturais, particularmente relevantes numa sociedade complexa. As várias combinações de modo de acesso a produtos culturais, valores e objetivos educacionais das famílias podem produzir distintas formas de relacionamento entre a cultura da escola e a cultura de seus alunos. Silva e Zanon compartilham com essa ideia ao destacar que a escola deve oferecer

[...] um ensino em que se tematiza o mundo da vida, ao mesmo tempo que se ensina a pensar, a se posicionar, a tomar conscienciosas decisões, a utilizar estratégias de pensamentos em resposta aos desafios vividos; um ensino que se preocupa em desenvolver e cultivar habilidades de pensamentos críticos, criativo, de resolução de problemas, no qual os modos de condução das aprendizagens implicam as formas dialógicas, reflexivas e de ação individual/coletiva refletida (SILVA; ZANON, 2000, p. 157).

Nesta concepção de tempo e de espaço da escola é que se desenvolve o tipo de ensino investigado neste trabalho. Constata-se que as atividades interativas propostas pelas professoras em sala de aula permitem aos estudantes maior envolvimento e participação. Outra questão que chama a atenção é a relação estabelecida entre o volume ocupado pelos plásticos encontrados no lixo e a sua massa. 
Dando sequência às atividades em classe, outros encaminhamentos foram feitos pelas professoras, emergindo novas compreensões acerca dos resíduos sólidos. A partir da determinação da composição gravimétrica do lixo foi possível determinar, a partir do conhecimento matemático, a quantidade de lixo produzido por cada estudante e por sua família. Também foi possível calcular a quantidade de lixo produzido por dia, semana e ano.

Concluímos que a intensificação das interações em sala de aula ocorre porque os sujeitos envolvidos no ensino e na aprendizagem têm um objeto em comum, sobre o qual conseguem dialogar tornando a aula mais interessante. Assim, ao trazer para discussão a questão dos resíduos sólidos gerados pelos próprios estudantes, é produzido um conhecimento escolar mais rico e contextual. Percebe-se, assim, que os sujeitos se constituem nas ações, interações e inter-relações uns com os outros. Nesse processo emergem "individualidades diferentes", dependendo de como cada um produz significados para si (HAMES, 2004, p. 147).

A mediação feita pela professora Carla incentivou os estudantes a se expressarem, fazendo da sala de aula um ambiente onde os alunos têm liberdade de expressão. A discussão de ideias entre educandos e educadores e a construção e interpretação de gráficos nas aulas de Química foram surgindo como bons aliados para a formação de conceitos mais sólidos. A partir de conhecimentos matemáticos, foi possível ainda determinar o volume de lixo transportado por cada caminhão responsável pela coleta, a quantidade de combustível e o custo de cada viagem realizada até o depósito do lixo, neste caso, o lixão de Ijuí.

Ao determinar a composição gravimétrica do lixo doméstico, os alunos tomaram consciência da quantidade de resíduos produzidos. As reflexões acerca do volume do lixo possibilitaram aos estudantes tomarem consciência da necessidade de reduzir a produção e reaproveitar o que for possível, conforme manifestação de Ednilson:

Eu não tinha noção do exagero de lixo que é produzido. Eu acredito que a maioria das pessoas não se dão conta disso, porque assim que o 
lixo é produzido ele é colocado em sacolas ou sacos de lixo e o caminhão leva embora. Mas os cálculos mostram uma quantidade assustadora. Seria interessante calcular quanto custa tudo isso.

A fala de Ednilson mostra como foi importante o fato de Carla ter se apropriado de conhecimentos matemáticos para discutir as questões relacionadas à geração e gerenciamento do lixo. Embora naquele momento não tenham sido discutidos a constituição química dos materiais encontrados no lixo e as formas como as substâncias que constituem esses materiais são transformadas, a introdução de conceitos matemáticos e a interpretação dos dados construídos a partir dos resíduos sólidos analisados foram suficientes para os estudantes tomarem consciência das consequências que estes resíduos podem trazer para o ambiente e para o homem.

Nesta mesma linha de pensamento, Marques (2006) observa que a sala de aula é um lugar social em que se dão as relações diretas do ensinar e aprender. Assim, ao propormos um ensino na concepção de SE, corroboramos com o autor no sentido de que

[...] a questão fundamental da sala de aula é a de explicitarem as bases conceituais em que se assenta o ensino-aprendizagem, processo que consiste em traduzir o plano da realidade vivida para o da idealidade dos conceitos e, em seguida, retraduzir o plano conceitual ao campo da vida cotidiana (MARQUES, 2006, p. 117).

Por sua vez, Maldaner e Araújo (1992, p. 20) defendem que o papel mais central da escola "[...] é o de investigar, problematizar e discutir os fatos, situações e coisas presentes no dia a dia dos educandos, de modo a lhes possibilitar novas formas de compreensão das realidades vividas, à luz e através do acesso ao saber estruturado, a ciência”. Marques concorda com esta questão argumentando

Não se ensinam ou aprendem coisas, mas relações estabelecidas em entendimento mútuo e expressas em conceitos, que, por sua vez, são construções históricas, isto é, nunca dadas de uma só vez, mas sempre retomadas por sujeitos em interação e movidos por interesses práticos no mundo em que vivem. Em vez de o professor operar com conceitos 
que já aprendeu e na forma em que os aprendeu e que agora só necessitariam ser reproduzidos nos e pelos alunos, trata-se, no ensino, de ele e os alunos produzirem, em entendimento comum, os conceitos com que irão operar para entenderem as relações com que lidam. Não se trata de chegar a soluções dadas às questôes/problemas, mas de inventar, em cada situação e por cada comunidade de sujeitos, os conceitos com que irão operar sobre os temas que analisam (MARQUES, 1993, p. 110).

A partir dos entendimentos construídos, concluímos que o desenvolvimento de propostas que contemplem situações reais e contextualizadas possibilitam romper com a estrutura tradicional do conhecimento escolar, numa lógica integradora de conceitos das diversas áreas do conhecimento, constituindo-se num espaço de significação amplo que articula temas, conteúdos, conceitos, procedimentos, valores e atitudes nos contextos de interação interdisciplinar.

Por outro lado, a organização curricular produzida na forma de SE envolve o reconhecimento da flexibilidade organizativa, não mais linear, mas com possibilidade de promover as inter-relações entre as diferentes áreas do conhecimento e contemplar os desafios impostos pelo cotidiano dos estudantes. Nessa lógica, o conhecimento escolar é construído no coletivo de diferentes sujeitos, engajados em processos sociais mais amplos.

\section{A escola como espaço de constituição profissional do docente}

A formação inicial e continuada de professores vem sendo foco de vários questionamentos, tais como: considerar a tarefa docente como simples transmissão de informações; desconhecer o papel da investigação sobre a prática pedagógica como constitutiva da autonomia do professor; a necessidade de criar espaços coletivos, no contexto escolar, para produção da pesquisa do e no ensino; a importância de constituir parcerias colaborativas entre professores em serviço e seus formadores na Licenciatura (BOFF; FRISON; ARAÚJO, 2005). 
Entendemos que é também nos espaços da escola, em especial nas salas de aula, cercados por estudantes, que estão os professores exercendo sua atividade e constituindo-se profissionais nos espaços sociais e históricos. As observações sistemáticas de práticas educativas sob o ângulo das ações que os docentes desenvolvem no cotidiano escolar tornam-se um espaço importante para a sua constituição.

Ao transitar da universidade para a escola e desta para a universidade, os professores em formação inicial e continuada podem tecer uma rede de relações, conhecimentos e aprendizagens, não com o objetivo de copiar, mas no intuito de compreender a realidade e as situações que se apresentam. Sobre essa temática Hames argumenta que

[‥] atingir as concepções dos professores, que são formas culturais anteriores produzidas nas interações sociais e internalizadas, torna-se mais fácil quando há desenvolvimento de ação coletiva, em que os sujeitos possam expressar seus pontos de vista, conhecimentos, modos de compreender o processo de ensino-aprendizagem, possibilitando, assim, a reconstrução e a ressignificação dessas concepções. Além de coletiva, a ação precisa ter continuidade no tempo, criando-se um movimento transformativo (HAMES, 2004, p. 148-149).

Assim, a vivência nos espaços cotidianos da escola e, de modo especial, a participação no desenvolvimento de aulas, compartilhando das dificuldades apresentadas pelos estudantes de $1^{\text {a }}$ série do nível médio para compreender determinados conceitos e de estabelecer relações entre estes conceitos numa situação real, possibilitam ao professor em formação inicial captar múltiplos processos de relações que identificam a escola como um lugar privilegiado de conhecimento sobre a prática educativa e de formação profissional, como se manifesta Iara, professora em formação inicial:

Como foi importante estabelecer relações entre os conceitos da Química com outras áreas, em especial da Matemática. Observar isso mostra que em alguns momentos é preciso parar a aula e trabalhar conceitos que muitas vezes não tínhamos planejado e que não são da nossa área. Essa 
era uma aula de Química, mas a professora precisou trabalhar conceitos matemáticos para avançar na compreensão dos conceitos químicos. Eu não sei se teria feito dessa forma. Penso que atribuiria a responsabilidade de explicar os conteúdos da Matemática ao professor de Matemática.

A manifestação de Iara deixa clara a dificuldade apresentada por ela em integrar os conteúdos específicos de sua área de formação com os conteúdos de outras áreas do conhecimento e, também, de relacioná-los com a vida real que ocorre fora dos muros escolares.

Neste rumo, Tardif (2002) comenta que a formação profissional do docente não se circunscreve apenas à sua formação acadêmica, que culmina na sua titulação, mas se constitui num "pluralismo epistemológico", que se encontra arraigado em suas origens sociais, como fonte de aquisição deste saber e seus modos de integração no trabalho docente. Para este autor, o professor é formado por muitos saberes, [...] entre eles os saberes provenientes da experiência na sala de aula, na escola, na experiência de seus pares.

A necessidade percebida pela professora de Química de introduzir os conceitos matemáticos indispensáveis para desenvolver a Situação de Estudo: Ambiente e vida: o ser humano neste contexto, mostra que o estudo das Ciências ou de qualquer disciplina não se justifica por si só. Para Lima e Silva (2007, p. 95), "[...] estudamos/ensinamos ciências para compreender coisas, processos, situações do mundo real e tecnológico no qual estamos inseridos". A maneira pela qual a professora de Química foi introduzindo e mediando os conceitos de outras áreas, em especial os da Matemática durante sua aula, permitiu que os estudantes tomassem consciência sobre as suas responsabilidades quanto à produção de resíduos sólidos.

Vários autores têm defendido a proposta de que a formação dos novos professores aconteça em espaços de interação com profissionais experientes. A oportunidade dada aos professores em formação inicial de observar, analisar e refletir sobre a aula produzida se constitui em processos formativos de futuros professores. Para Zeichner: 
Reflexão também significa o reconhecimento de que o processo de aprender a ensinar se prolonga durante toda a carreira do professor e de que, independentemente do que fazemos nos programas de formação de professores e do modo como fazemos, no melhor dos casos só podemos preparar os professores para começarem a ensinar. Com o conceito de ensino reflexivo, os formadores de professores têm a obrigação de ajudar os futuros professores a interiorizarem, durante a formação inicial, a disposição e a capacidade de estudarem a maneira como se ensina e de melhorar com o tempo, responsabilizando-se pelo seu próprio desenvolvimento profissional (ZEICHNER, 1993, p. 17).

Assim entendido, é importante conhecer as implicações dos processos formativos da docência na prática pedagógica, identificando quais saberes são mobilizados, como e em que momentos são postos em prática, pois o espaço da escola é, na maioria das vezes, um espaço desconhecido. É por meio das práticas e relações pedagógicas que o professor manifesta os seus saberes, ou seja, não os coloca de uma forma homogênea, igualitária, mas prioriza-os e valoriza-os de acordo com as necessidades postas pela realidade de sala de aula (TARDIF, 2002). Para, para este autor, portanto,

[...] o saber dos professores não é um conjunto de conteúdos cognitivos definidos de uma vez por todas, mas um processo em construção ao longo de uma carreira profissional na qual o professor aprende progressivamente a dominar seu ambiente de trabalho, ao mesmo tempo em que se insere nele e o interioriza por meio de regras de ação que se tornam parte integrante de sua "consciência prática" (TARDIF, 2002, p. 14).

Quando tratamos dos saberes disciplinares numa perspectiva integradora e a partir de um profundo engajamento da realidade de cada sujeito envolvido, num processo, que necessita estar em permanente criação e recriação (BOFF et al., 2007), oportunizamos uma reflexão sobre as práticas vivenciadas no espaço escolar. Em consonância com essa ideia, Tardif argumenta que

[...] os saberes profissionais são variados e heterogêneos porque os professores, na ação, no trabalho, procuram atingir diferentes tipos de conhecimento, de competência ou de aptidão. Dizendo 
de outra maneira, a prática profissional dos professores é heterogênea ou heterônoma no tocante aos objetivos internos da ação e aos saberes mobilizados. Por exemplo, quando observamos professores trabalhando em sala de aula, na presença dos alunos, percebemos que eles procuram atingir, muitas vezes de forma simultânea, diferentes tipos de objetivos: procuram controlar o grupo, motivá-lo, levá-lo a se concentrar em uma tarefa, ao mesmo tempo em que dão uma atenção particular a certos alunos da turma, procuram organizar atividades de aprendizagem, acompanhar a evolução da atividade, dar explicaçôes, fazer com que os alunos compreendam e aprendam (TARDIF, 2000, p. 14).

Neste sentido, acreditamos que a proposição/elaboração de SE vem possibilitando aprendizagens mais significativas dos conceitos escolares e um olhar "crítico" aos currículos desenvolvidos nas escolas de Educação Básica. Tempos e espaços criados e discussões produzidas, na escola, acerca da produção e execução de propostas inovadoras que permitem uma reorganização dos conteúdos escolares, propiciam autonomia e autoria aos sujeitos nas suas ações pessoais e profissionais.

Essa forma de desenvolver os conteúdos escolares exige que o professor tenha um bom conhecimento da temática a ser estudada para que deste modo possa estimular nos alunos o interesse pelo estudo e o envolvimento nas atividades. Entendemos que o ato de ensinar é uma tarefa complexa e que requer dos professores a mobilização de vários saberes oriundos de diversas fontes, pois conforme salientam Perrenoud et al. (2001),

[...] o ensino não pode ser analisado unicamente em termos de tarefas de transmissão de conteúdos e de métodos definidos a priori, uma vez que são as comunicações verbais em classe, as interaçốes vivenciadas, a relação e a variedade das ações em cada situação que permitirão, ou não, a diferentes alunos, o aprendizado em cada intervenção (PERRENOUD et al., 2001, 26).

As observações e as análises produzidas por esta pesquisa possibilitam afirmar que a SE é uma concepção pedagógica potencial que permite e exige a mobilização de diferentes saberes para 
compreender questóes complexas e socialmente relevantes, como foi o caso dos resíduos sólidos produzidos pela atividade humana.

\section{Considerações finais}

O desenvolvimento de conteúdos escolares que conduz à integração dos conhecimentos de diversas áreas produz uma nova forma de abordagem dos conceitos na Educação Básica, com o acesso a importantes e novas linguagens constitutivas de pensamentos mais abertos e fecundos, baseados em conhecimentos socialmente relevantes.

A análise do trabalho desenvolvido mostra que a aprendizagem de conceitos é muito mais complexa do que se acredita poder fazer pelo simples estabelecimento de definições consagradas nos livros didáticos. Acreditamos que por trás da proposta metodológica se escondem valores e ideias em relação aos processos de ensinar e aprender e concepçóes de conhecimento e de ciência que norteiam a prática pedagógica dos professores.

Por intermédio da mediação, foi oportunizada a interlocução entre conhecimentos iniciais dos estudantes e outros mais elaborados - os escolares. A conexão dos conceitos entre as diversas áreas, na compreensão de situações da vivência dos estudantes, como foi a Situação de Estudo: Ambiente e vida: o ser humano neste contexto, proporciona a evolução destes conceitos num nível de maior complexidade.

O reconhecimento de situações conceitualmente ricas e próximas dos estudantes permite desenvolver, de forma articulada, conceitos de diferentes áreas necessários para a compreensão da temática estudada. A realização de atividades contextualizadas, vinculadas à vivência dos alunos, que facilitem a formação de ideias que despertam a conscientização para a produção racional e tratamento adequado para o lixo foi uma questão relevante.

Edwards e Mercers (1987, apud ROSA, 2004), todavia, advertem que a construção do conhecimento em sala de aula é 
papel de um processo comunicativo de negociação social, por intermédio do qual os significados e a linguagem do professor são apropriados pelos estudantes na construção de um conhecimento. Assim, a análise das aulas revela que as formas de participação possibilitadas e as atividades realizadas durante o desenvolvimento da proposta de ensino facilitam a interação pedagógica necessária à construção da aprendizagem significativa e articulada nos diferentes contextos dos conceitos científicos.

Sobre as concepções do ambiente, as ideias já construídas pelos estudantes no meio social e cultural interferem na produção de novos sentidos e significados. Esses dizeres se referem às ideias de ambiente dos alunos, mas também, e principalmente, da forma como os professores se relacionam com os já ditos (ORLANDI, 1999) em relação à questão da produção e gerenciamento do lixo domiciliar e os problemas gerados quando este não for tratado adequadamente. Esta visão interferiu no aprofundamento de algumas ideias centrais consideradas significativas para a compreensão dessa temática e que diz respeito à constituição e transformação dos materiais encontrados no lixo. Detectamos, também, as dificuldades apresentadas pelas professoras em estabelecer relações entre os conteúdos tradicionais de sua disciplina, a Química, e as possibilidades de inserção desses conteúdos na questão ambiental e na interação com outras áreas do conhecimento, que no caso desta análise, diz respeito à Matemática. Quando, no entanto, é dada a oportunidade aos alunos para ocuparem o espaço da sala de aula, como sujeitos da aprendizagem, eles passam a ter prazer em desenvolver as atividades e a se assumirem autores da aula.

O acompanhar, analisar e refletir sobre as manifestações dos estudantes e da professora em formação inicial, bem como a condução do trabalho desenvolvido pela professora da escola deixam claro que o desenvolvimento de conteúdos de Química articulados aos conhecimentos matemáticos e relacionados a situações de vivência é importante e produz resultados significativos. Muitas vezes, porém, não são desenvolvidos devido a sua complexidade e por exigirem do professor um tempo maior de 
estudo e planejamento que nem sempre eles dispõem, gerando insegurança. A reflexão sobre o trabalho desenvolvido expressa que pensar a educação num determinado contexto é pensar a ação educativa, processada de acordo com a compreensão da realidade social em que se está inserido.

\section{Referências}

AUTH, Milton Auth et al. Situação de Estudo na área de Ciências do Ensino Médio: rompendo fronteiras disciplinares. In: MORAES, Roque; MANCUSO, Ronaldo. (Orgs.). Educação em Ciências: produção de currículo e formação de professores. Ijuí: Ed. Unijuí, p. 253-276, 2004.

BOFF, Eva Teresinha de Oliveira; FRISON, Marli, Dallagnol; ARAÚJO, Maria Cristina Pansera de. Significação dos Conceitos de Ciências Naturais e suas Tecnologias numa Perspectiva Interdisciplinar: Análise de uma Situação de Estudo. In: V ENPEC, 2005, Bauru- SP.

BOFF, Eva Teresinha de Oliveira et al. Situação de Estudo: Uma Possibilidade de Reconstrução de Teorias e Práticas Docentes. In: MORTIMER, Eduardo Fleury (Org.). Anais do VI Encontro Nacional de Pesquisa em Educação em Ciências. Belo Horizonte: Abrapec. 2007 [CDROM.].

BRASIL, Ministério da Educação. Parâmetros Curriculares Nacionais PCN-CIÊNCIAS 1997. Brasília: 1997.

CARR, Wilfred; KEMMIS, Stephen. Teoria crítica de la enseñanza: La investigación-acción en la formación del profesorado. Barcelona-España: Martinez Rocca, 1988.

DAVIDOV, Vasili. La enseñanza escolar y el desarrollo psíquico. Investigación psicológica, teórica y experimental. Moscou, Editorial Progresso, 1998.

DOLL, Willian. Currículo: uma perspectiva pós-moderna. Porto Alegre: Artmed, 1997.

ELLIOTT, John. Recolocando a pesquisa-ação em seu lugar original e próprio. Tradução de PEREIRA, E. M. A. In: GERALDI, Corinta Maria Grisolia; FIORETII, Dario; PEREIRA, Elisabete Monteiro de Aguiar 
(Orgs.). Cartografia do trabalho docente - professor (a)- pesquisador (a). Campinas: Mercado de Letras, 1998.

FREIRE, Paulo. Conscientização, teoria e prática da libertação: uma introdução ao pensamento de Paulo Freire. 3 ed. São Paulo: Moraes, 1980.

FRISON, Marli Dallagnol. A não aprendizagem escolar como fator determinante de exclusão social no Ensino Médio. Ijuí: Ed. Unijuí, 2000.

HAMES, Clarinês. Evolução dos espaços interativos de formação de professores de Ciências na Unijuí. In: MORAES, Roque; MANCUSO, Ronaldo (Orgs.). Educação em Ciências: produção de currículos e formação de professores. Ijuí: Ed. Unijuí, p. 135-155, 2004.

LIMA, Maria Emília Caixeta de Castro; SILVA, Nilma Soares da. A Química no Ensino Fundamental: uma proposta em ação. In: ZANON, Lenir Basso; MALDANER, Otavio Aloisio (Orgs.). Fundamentos e Propostas de Ensino de Química para a Educação Básica. Ijuí: Ed. Unijuí, p. 89-107, 2007.

LOPES, Alice Ribeiro Casimiro. Conhecimento escolar: inter-relações com conhecimentos científicos e cotidianos. In: Contexto e Educação. Ijuí: Unijuí, jan./mar. p.40-59, 1997.

MACHADO, Andréa Horta. Aulas de Química: discurso e conhecimento. Ijuí: Ed. Unijuí, 1999, 200p.

MALDANER, Otavio Aloisio; ZANON, Lenir Basso. SE: uma organização curricular que extrapola a formação disciplinar em ciências. Espaço da escola, v. 1, n. 41, p. 45-60, jul./set 2001.

MALDANER, Otavio Aloisio; ARAÚJO, Maria Cristina Pansera de. A participação do professor na construção do currículo escolar em ciências. In: Espaço da Escola. Ed. Unijuí, n. 3, p. 18-28, jan./mar., 1992.

MARQUES, Mario Osório. A aprendizagem na mediação social do aprendido e da docência. Ijuí: Unijuí, 2006.

MARQUES, Mario Osório. Conhecimento e Modernidade em Reconstrução. Ijuí: Ed. Unijuí, 1993.

MORAES, Roque; GOMES, Vanise. Dissoluções e Cristalizações. In: MORAES, Roque; MANCUSO, Ronaldo (Orgs.). Educação em Ciências - Produção de currículos e formação de professores. Ijuí: Ed. Unijuí, 2004, 304p. 
MORIN, Edgar. A cabeça bem-feita. Rio de Janeiro: ed. BCD, 2001.

OLIVEIRA, Valeska Fortes de. Imaginário Social e Escola de Segundo Grau. Ijuí: Ed. Unijuí, 1997.

ORLANDI, Eni. Análise de discurso: Princípios e procedimentos. Campinas: Pontes, 1999.

PERRENOUD, Philippe et al. Formando Professores Profissionais: três conjuntos de questões. In: PAQUAY, Léopold. et al. (Orgs.). Formando Professores Profissionais: Quais estratégias? Quais competências? Porto Alegre: Artmed Editora, 2001.

ROSA, Maria Inês Petrucci. Investigação e Ensino: Articulações e possibilidades na formação de professores de Ciências. Ijuí: Ed. Unijuí, 2004.

SACRISTÁN, Gimeno José. Uma reflexão sobre a prática. Porto Alegre: Artmed, 1998.

SILVA, Lenise Heloísa de Arruda; ZANON, Lenir Basso. A experimentação no ensino de Ciências. In: SCHNETZLER, Roseli Pacheco; ARAGÃO, Rosália de. Ensino de Ciências: Fundamentos e abordagens. Campinas: R. Vieira Gráfica e Editora LTDA, 2000.

SILVA, Tadeu. O Currículo como Fetiche: a poética e a política do texto curricular. Belo Horizonte, 2006.

TARDIF, Maurice. Saberes profissionais dos professores e conhecimentos universitários: elementos para uma epistemologia da prática profissional dos professores e suas conseqüências em relação à formação para o magistério. In: Revista Brasileira de Educação. Campinas: Autores Associados, n. 13, p. 5-24, 2000.

TARDIF, Maurice. Saberes docentes e formação profissional. Petrópolis: Vozes, 2002.

ZEICHNER, Kenneth. A formação reflexiva de professores: Idéias e Práticas. Lisboa: Educa Professor, 1993. 